\title{
Metodologia comparada: percepções para formação docente acerca de conjuntos numéricos ${ }^{1}$
}

\author{
Compared methodology: perceptions for teacher formation upon \\ numerical sets \\ Méthodologie comparative: des idées pour la formation des enseignants sur les \\ ensembles de nombres
}

Vlademir Marim²

Universidade Federal de Uberlândia

Neiva de Castro Cardoso Andraus ${ }^{3}$ Secretaria Estadual de Educação de Minas Gerais

Resumo: Essa pesquisa foi desenvolvida no Programa de Pós-Graduação de Ensino de Ciências e Matemática da Univerisdade Federal de Uberlândia e tem como objetivo analisar as práticas pedagógicas dos docentes que atuam no $1^{\circ}$ ano do Ensino Médio, por meio da metodologia comparada, explicitando as fases: descritiva, interpretativa, justaposição e comparativa, com enfase no conteúdo de conjuntos numéricos, com interface na resolução de problemas, por meio de registros dos cadernos dos alunos. Como pressupostos teóricos abordou-se: Marcelo (2009), Marim e Manso (2018), Nóvoa (2009), Tardif (2000), Freire (2009), as Diretrizes Curriculares Nacionais (2015), a Base Nacional Comum Curricular (2018) entre outros. Os registros desvelaram práticas individualizadas entre os professores, no desenvolvimento do conteúdo. Sugere-se organizar um ambiente de partilha, no qual possa ser discutido o planejamento, inteirarse dos conteúdos e, em sincronia, organizar as práticas diárias entre pares.

Palavras-chave: Ensino Médio. Resolução de problemas. Formação continuada. Educação Matemática. Ensino da Matemática.

Abstract: This search was developed in the Graduate Program of Science and Mathematics Teaching at the Federal University of Uberlândia, which aims to analyze the pedagogical practices of teachers who work in the 1st year of high school, through the compared methodology, explaining the phases: descriptive, interpretative, juxtaposition and comparative, with an emphasis on the content of numerical sets with an interface in solving problems, through records of students' notebooks. The following theoretical assumptions were addressed: Marcelo (2009); Marim and Manso (2018);

$1 \mathrm{O}$ artigo foi elaborado com base nos dados e análise decorrentes da pesquisa de Mestrado realizada na Universidade Federal de Uberlândia e intitulada "Metodologia comparada: percepções para formação docente acerca de conjuntos numéricos".

${ }^{2}$ Doutor em Educação - Currículo pela Universidade Católica de São Paulo (PUC/SP) e pós-doutor em Políticas Públicas em Formação Docente pela Universidade Autonoma de Madrid (UAM). Professor da Universidade Federal de Uberlândia (UFU). Lattes: http://lattes.cnpq.br/8618346653372477. E-mail: marim@ufu.br. ORCID: https://orcid.org/0000-0002-4754-8802.

${ }^{3}$ Mestra em Ensino de Ciências e Matemática pela Universidade Federal de Uberlândia (UFU). Professora efetiva da rede Estadual de Educação de Minas Gerais (SEE/MG) e da Secretaria Municipal de Educação e Cultura da cidade de Ituiutaba (SME). Lattes: http://lattes.cnpq.br/2534780679642096. E-mail: neivandraus@gmail.com. ORCID: https://orcid.org/0000-0002-1032-5517. 
Revista Educação e Políticas em Debate - v. 10, n. 2, p. 819-837, mai./ago. 2021 - ISSN 2238-8346

Nóvoa (2009); Tardif (2000); Freire (2009); DCN (2015); BNCC (2018); and others. The records revealed individualized practices among teachers in the development of content. It is suggested to organize a sharing environment, in which planning can be discussed, learn about the contents and, in sync, organize your daily practices among peers.

Keywords: High School. Problem solving. Continuing formation. Mathematical Education. Mathematics Teaching.

Résumés:Cette recherche a été développée dans le Programme de de spécialisation des Sciences et des Mathématiques de l'Université Fédérale d'Uberlândia, qui vise à analyser les pratiques pédagogiques des enseignants qui travaillent dans la 1ère année de lycée, à travers la méthodologie comparative, en expliquant les phases : descriptive, interprétative, juxtaposition et comparative, en mettant l'accent sur le contenu des ensembles de nombres avec interface dans la résolution de problèmes, à travers les enregistrements des cahiers des élèves. Comme hypothèses théoriques abordées: Marcelo (2009) Marim et Manso (2018); Nóvoa (2009); Tardif (2000); Freire (2009); DCN (2015); BNCC (2018); et autres. Les dossiers ont révélé des pratiques individualisées chez les enseignants en matière de développement de contenu. Il est suggéré d'organiser un environnement de partage, dans lequel la planific ation peut être discutée, prendre conscience des contenus et, en synchronisation, organiser leurs pratiques quotidiennes entre pairs.

MOTS CLÉS: Lycée. Résolution de problèmes. Formation continue. Enseignement des mathématiques. Enseignement des mathématique.

Recebido em: 18 de maio de 2020 Aceito em: 30 de dezembro de 2020

\section{Introdução}

Essa pesquisa foi desenvolvida no Programa de Pós-graduação de Ensino de Ciências e Matemática (PPGECM) - Mestrado profissional - da Universidade Federal de Uberlândia (UFU), com apoio da Secretaria Municipal de Educação e Cultura de Ituiutaba.

Um dos papéis do professor consiste em buscar alternativas para produzir conhecimentos, na perspectiva de refletir sobre a própria prática e meios para melhorála. Ser professor investigador nos remete à ideia de procurar respostas para determinados problemas, buscar comprovações científicas para dar suporte às metodologias, refletir sobre caminhos percorridos e incitar provocações para novos questionamentos, a fim de redirecionar as práticas pedagógicas.

Nessa perspectiva, o objetivo desse trabalho é analisar as práticas pedagógicas dos docentes que atuam no $1^{\circ}$ ano do Ensino Médio, por meio da metodologia de educação comparada, abordando o conteúdo de conjuntos numéricos, com interface na resolução de problemas, através de registros apontados por alunos do $1^{\circ}$ ano do Ensino Médio da Educação Básica de uma escola pública do estado de Minas Gerais. 
Revista Educação e Políticas em Debate - v. 10, n. 2, p. 819-837, mai./ago. 2021 - ISSN 2238-8346

Para o desenvolvimento do objetivo geral, pretende-se, como objetivos específicos: (a) compreender os pressupostos teóricos que abordam o desenvolvimento do profissional docente e as concepções da formação continuada; (b) analisar os registros dos sujeitos, por meio da metodologia de educação comparada; (c) comparar registros dos alunos do $1^{\circ}$ ano no Ensino Médio, de cinco professores, referentes aos conteúdos de conjuntos, pautados na metodologia de resolução de problemas; e (d) identificar, comparar e analisar as metodologias utilizadas pelos cinco profess ores do Ensino Médio, em especial no $1^{\circ}$ ano, referentes ao conteúdo de conjuntos.

Nesse contexto, emerge o seguinte problema de pesquisa: As práticas pedagógicas desenvolvidas pelos professores do $1^{\circ}$ ano do Ensino Médio, em relação aos conjuntos numéricos, com interface na resolução de problemas, por meio dos registros apontados pelos alunos, explicitam os conhecimentos e saberes docentes?

No intuito de responder ao problema apresentado nessa investigação, foram analisados os registros dos alunos do $1^{\circ}$ ano do Ensino Médio de uma escola pública estadual do município de Ituiutaba, abordando o conteúdo de conjuntos, sob a óptica da metodologia comparada. Essa abordagem foi feita em sincronia com a metodologia de resolução de problemas. Também foi realizada uma comparação do contexto social, político e econômico do Brasil, do estado de Minas Gerais e do município de Ituiutaba.

O desenvolvimento da pesquisa na escola envolveu as seguintes ações: (a) descrição de cinco classes; (b) acesso aos registros de cinco cadernos, de cinco alunos, e avaliações de cinco professores; (c) coleta de dados de documentos arquivados na secretaria da escola, sobre o perfil de alunos e professores; e (d) estudo de documentos oficiais do governo: Parâmetros Curriculares Nacionais (PCN), Currículo Básico Comum (CBC) a Base Nacional Comum Curricular (BNCC), e as Diretrizes Curriculares Nacionais (DCN).

$\mathrm{Na}$ perspectiva da Metodologia Comparada, possivelmente foram desveladas realidades marcantes, com diferenças e semelhanças do contex to social, político, econômico e educacional do Brasil, Minas Gerais, Ituiutaba, e específicamente, de uma escola pública da cidade desse município.

\section{Formação Profissional: saberes docentes}

Ser professor, na atual perspectiva, significa admitir que é necessário procurar meios para continuar a aprender e investir em formação, haja vista a aceleração e agilidade das informações, bem como as muitas possibilidades de novas descobertas e conhecimentos.

$\mathrm{Na}$ construção do ser professor, Marim e Manso (2018) descrevem a autonomia 
Revista Educação e Políticas em Debate - v. 10, n. 2, p. 819-837, mai./ago. 2021 - ISSN 2238-8346 docente como qualidade educativa, com possibilidades de realizar intervenções nas decisões políticas referentes às escolas, pensando em ações interventivas para aprovação de programas escolares que possam ser utilizados para o bem comum.

De acordo com Marcelo (2009), mesmo diante das realidades vivenciadas na formação inicial, existe uma insatisfação originária das instâncias políticas e da classe docente, cujas críticas abordam alguns aspectos, tais como: a fragmentação de conteúdos, a burocratização nas instituições, os vínculos fragilizados com a escola e a dissociação entre teoria e prática.

Nesse cenário, Nóvoa (2009) discorre sobre as habilidades e competências de um bom professor. O autor defende que é impossível definir o "bom professor", a não ser por meio de listas intermináveis de habilidades, cuja simples enumeração se tornaria insuportável. Porém, é possível refletir sobre apontamentos integradores do trabalho docente no contexto da sociedade contemporânea.

Na concepção de ser um bom professor, Tardif (2000) referencia o pragmatismo do ato de ensinar e preconiza que, além dos conhecimentos científicos, devem ser considerados, no planejamento das práticas educativas, aspectos emocionais, sociais, cognitivos e coletivos.

Os professores utilizam os saberes originários de suas experiências, aliados aos conhecimentos científicos e didáticos, no desenvolvimento do trabalho docente. Desse modo, o ensino e a aprendizagem dependem da interconexão dos mesmos, tendo em vista um trabalho pautado em produções diferenciadas e significativas.

O termo "saberes" tem um sentido polissêmico, é construído pela experiência do sujeito. No "saber", a informação é externa ao assunto, é de ordem social e está situada entre a interface de conhecimento e informação (PAQUAY et al., 2005). Por outro lado, quando se refere a conhecimentos, Tardif (2000) destaca que um professor se serve de sua cultura pessoal, advinda de sua história de vida, sua cultura escolar anterior e conhecimentos disciplinares oriundos da universidade.

No que se refere aos conhecimentos e saberes, a Diretrizes Curriculares Nacionais DCN (2015), em seu Art. 13, versam sobre o trabalho docente, que está organizado por componentes curriculares, campos de conhecimentos e/ou interdisciplinares. Nesse sentido, deve-se priorizar a integralidade da Educação Básica, abarcando aspectos diversos, como: a) ensino; b) gestão educacional; c) processos educativos escolares e não escolares; e d) produção e difusão do conhecimento científico, tecnológico e educacional.

No desenvolvimento da carreira profissional, que acontece durante a formação incial e na formação continuada, preocupa-se com o exercer da docência de maneira competente. Braslavsky (1999) apud Puentes, Aquino e Neto (2009), conceitua a terminologia competência sobre a docência como a capacidade de fazer com saber e com consciência. 
Revista Educação e Políticas em Debate - v. 10, n. 2, p. 819-837, mai./ago. 2021 - ISSN 2238-8346

Pensando na ideia deste autor, Marim (2011) pontua várias competências docentes, tais como: desenvolvimento da integridade intelectual; competência visual, linguística estética e imaginativa - priorizando os discursos intra e interculturais distintos; e o desenvolvimento da análise política global e de competências - como a comunicação, resolução de problemas e mediação de conflitos.

Nesse contexto, é necessário priorizar, na formação docente, as competências básicas de aprendizagem e desenvolvimento, organização e funcionamento do processo cognitivo, bem como os valores e atitudes e a reflexibilidade diante dos meios de comunicação.

Refletindo sobre a conexão entre o ensino, suas competências e a aprendizagem discente, a Base Nacional Comum Curricular (BNCC) (BRASIL, 2018) define objetivos de aprendizagem dos componentes curriculares estabelecidos para toda a Educação Básica, tendo em vista o desenvolvimento global do aluno. Essa base prioriza alguns aspectos, como: a superação da fragmentação disciplinar do conhecimento; o estímulo à sua aplicação na vida real; o protagonismo do aluno em sua aprendizagem; e a importância do contexto para dar sentido ao que se aprende. Nesse sentido, uma das maneiras de ressignificar o conhecimento do estudante pode ser a utilização do registro.

Duval (2012) relata o paradoxo cognitivo sobre as representações semióticas: as apreensões dos objetos não podem ser mais que conceituais. Acredita-se, também, que somente por meio de representações semióticas as atividades sobre objetos se tornam possíveis. A palavra "representação" pode ser identificada por meio de uma escrita, uma notação ou por um símbolo matemático: um número, uma função, um vetor etc. De maneira análoga, os traçados e figuras representam objetos matemáticos - um segmento, um ponto, um círculo, dentre outros; no entanto, os objetos não podem ser confundidos com símbolos.

Na óptica de Freire (2009), o registro é história, memória individual ou coletiva perpetuada na palavra grafada; é um exercício no processo de apropriação do pensamento. Por meio do registro, pode ocorrer a sistematização de um estudo ou de uma situação de aprendizagem. No entanto, é preciso selecionar o que é relevante a ser registrado.

Entre os diversos tipos de registro está o caderno escolar, um dos recursos didáticos mais frequentemente utilizados nas escolas. Pesquisas na área de educação têm utilizado os cadernos como fonte de informações, para compreender aspectos do cotidiano escolar, principalmente nas pesquisas de caráter histórico. Para conhecer as informações registradas nos cadernos e identificar os métodos educacionais, faz-se necessário saber como foram elaborados, como são utilizados e de que forma se inserem no contexto escolar (PERETTA; SOUZA, 2005). 


\section{Cenário da pesquisa: categorias, parâmetros e indicadores}

A metodologia comparada utiliza-se de análises e comparativos de contextos distintos e/ou similares, que podem propiciar o compartilhamento de práticas, objetivando a implementação e manutenção de políticas públicas que viabilizem a construção do conhecimento, não só na educação, mas em diversos setores e espaços.

Nessa dialógica, a metodologia comparada pode ser empregada de forma profícua, de modo a contribuir eficazmente para o ensino e a aprendizagem, no sentido de incentivar a pesquisa e novas descobertas, por meio da comparação de contextos similares e/ou divergentes.

Dessa forma, a metodologia comparada embasa a presente pesquisa, e inicia-se com o estudo de parte do cenário brasileiro, no qual é elucidado o contex to político, econômico, sociocultural e educacional do país. Algumas fases perpassam o desenvolvimento dessa metodologia, e essas fases fundamentam o trabalho científico de maneira objetiva e sistematizada, sendo: (a) descritiva; (b) interpretativa; (c) justaposição; e (d) comparativa ou explicativa. Posto isso, é necessário que as observações e campos de estudos envolvam: (a) fenômenos observáveis; (b) pluralidade de fatos (no mínimo, dois, pois não há como realizar comparação com um único elemento); (c) uniformidades (semelhanças dos fatos comparados); e (d) heterogeneidades (naturezas diferentes dos objetos).

A priori, nesta primeira fase, denominada descritiva, coletou-se dados em documentos oficiai,s como: Programa Internacional de Avaliação de Estudantes (PISA), Instituto Brasileiro de Geografia e Estatística (IBGE), Instituto Nacional de Estudos e Pesquisas Educacionais Anísio Teixeira (INEP), Educasenso, Ministério da Educação (MEC), Secretaria de Estado de Educação (SEE), Programa de Avaliação da Rede Pública da Educação Básica (PROEB), Programa Internacional de Avaliação de Estudantes (PISA). Nesses documentos, foram observadas informações sobre população, extensão territorial, unidades administrativas, Produto Interno Bruto (PIB) e outras.

O contex to educacional também foi alvo de investigação, de modo que foram descritos os desafios e as perspectivas a serem alcançados, além da coleta minuciosa de dados sobre o número de escolas, matrículas e docentes, por dependências administrativas (municipal, estadual, federal e privada).

Posteriormente, nesta investigação, descreveram-se os dados do estado de Minas Gerais, com o intuito de analisar a economia, política, população, cultura, educação e outros aspectos do referido estado. Nessa óptica, foi necessário coletar e organizar os dados sobre o 
Revista Educação e Políticas em Debate - v. 10, n. 2, p. 819-837, mai./ago. 2021 - ISSN 2238-8346 contexto educacional, o número de escolas, matrículas e docentes em suas respectivas dependências administrativas, similares à linha de pesquisa do contex to brasileiro.

De forma análoga aos processos anteriores, foram desenvolvidas investigações sobre as mesmas abordagens, envolvendo, no entanto, a esfera municipal da cidade de Ituiutaba. Dentre os registros organizados sobre este municipio, encontram-se os estudos e investigações da Escola Estadual Governador Israel Pinheiro (EEGIP), que, seguindo as mesmas performances anteriores, também fez parte desse movimento de investigação.

Nessa escola, foi estudado, em termos gerais, o perfil da unidade de ensino, analisandose os seguintes aspectos: contex to histórico, estrutura, espaço físico, quadro de profissionais, número de alunos, aspectos pedagógicos e metodológicos. De forma similar foram analisados também dados sobre os sujeitos da pesquisa: os professores, as turmas e os cadernos dos alunos que apresentam registros sobre a metodologia de resolução de problemas em interface ao conteúdo de conjuntos, para futuras analogias.

Após especificar os registros que aboradaram alguns aspectos sociopolítico e educativo da realidade brasileira, do estado de Minas Gerais, do município de Ituiutaba e da unidade escolar, foi realizada a comparação dos apontamentos dos alunos, registrados em seus cadernos, no intuito de analisar, efetuar conexões, bem como compreender e propor ações que possibilitem contribuições para o processo de ensino e aprendizagem, no que se refere à temática "conjuntos numéricos".

Após a catalogação de dados, construiu-se a árvore de categorias, parâmetros e indicadores (quadro 1), a qual possibilitou a sistematização de informações e, posteriormente, a justaposição e comparação dos elementos indicados. 
Revista Educação e Políticas em Debate - v. 10, n. 2, p. 819-837, mai./ago. 2021 - ISSN 2238-8346

Quadro 1 - Árvores de Categorias, Parâmetros e Indicadores.

\begin{tabular}{|c|c|c|}
\hline CATEGORIAS & PARÂMETROS & INDICADORES \\
\hline \multirow{10}{*}{$\begin{array}{l}1 \text { Profissional docente } \\
\text { e perfil discente }\end{array}$} & \multirow{3}{*}{$\begin{array}{l}\text { 1.1 Perfil da trajetória do docente } \\
\text { no contex to educacional }\end{array}$} & 1.1.1 Idade \\
\hline & & 1.1.2 Tempo de serviço na educação \\
\hline & & 1.1.3 Tempo de serviço na escola \\
\hline & \multirow{3}{*}{1.2 Formação docente } & 1.2.1 Ano de término da formação inicial \\
\hline & & 1.2.2 Ano inicial da profissão docente \\
\hline & & 1.2.3 Tempo de formação continuada \\
\hline & \multirow[t]{4}{*}{1.3 perfil do discente } & 1.3.1 Turno/ número de alunos por turma \\
\hline & & 1.3.2 Acatamento \\
\hline & & 1.3.3 Participação \\
\hline & & 1.34 Histórico \\
\hline \multirow{13}{*}{$\begin{array}{l}\text { 2.Conhecimentos } \\
\text { científicos, pedagógicos } \\
\text { e metodológicos }\end{array}$} & \multirow{4}{*}{ 2.1 Planejamento } & 2.1.1Conteúdo desenvolvido \\
\hline & & 2.1.2 Objetivo referente ao conteúdo \\
\hline & & 2.1.3 Metodologia utilizada \\
\hline & & $\begin{array}{llll}\text { 2.1.4 Período previsto } & \text { para } & \text { o } \\
\text { desenvolvimento do conteúdo } & & \end{array}$ \\
\hline & \multirow[b]{2}{*}{ 2.2 Abordagem ao tema } & 2.2.1 Conhecimentos prévios \\
\hline & & 2.2.2 Introdução ao tema \\
\hline & \multirow{4}{*}{ 2.3 Desenvolvimento do tema } & 2.3.1 Estrutura lógica utilizada \\
\hline & & $\begin{array}{l}\text { 2.3.2 Valorização do Registro, por meio dos } \\
\text { cadernos dos alunos }\end{array}$ \\
\hline & & $\begin{array}{l}\text { 2.3.3 Utilização do material didático } \\
\text { pedagógico }\end{array}$ \\
\hline & & 2.3.4 Tempo de aprendizagem \\
\hline & \multirow{3}{*}{ 2.4 Avaliação } & 2.4.1 Tipo de avaliação \\
\hline & & 2.4.2 Objetivo da avaliação \\
\hline & & $\begin{array}{l}\text { 2.4.3 Quantidade de questões referente aos } \\
\text { conjuntos numéricos }\end{array}$ \\
\hline
\end{tabular}

Fonte: Construído pelos autores.

O quadro 1 apresenta o perfil dos docentes e dos discentes envolvidos na pesquisa, além dos conhecimentos científicos, pedagógicos e metodológicos expostos nos registros dos cadernos dos alunos. De forma esquemática, as categorias abordadas na investigação se dividem em duas: a) profissional docente e perfil discente; e b) conhecimentos científicos, pedagógicos e metodológicos. Essas categorias apresentam parâmetros e indicadores específicos, de acordo com a temática.

A categoria profissional docente e o perfil discente envolveram os seguintes parâmetros: perfil da trajetória do docente no contexto educacional (idade, tempo de serviço 
Revista Educação e Políticas em Debate - v. 10, n. 2, p. 819-837, mai./ago. 2021 - ISSN 2238-8346 na educação e na escola); e, formação docente e perfil discente (ano de término da formação inicial, ano inicial da profissão, tempo de formação continuada e perfil da turma).

A categoria conhecimentos científicos, pedagógicos e metodológicos aborda alguns parâmetros, tais como: planejamento (conteúdo desenvolvido, objetivos, tempo previsto para o desenvolvimento e metodologia utilizada); abordagem do tema (conhecimentos prévios e introdução ao tema); desenvolvimento do tema (período de desenvolvimento, estrutura lógica, valorização do registro, utilização do material didático pedagógico); e avaliação (tipo de avaliação, objetivo, quantidade de questões referente a conjuntos numéricos).

Posto isto, entendemos que a primeira categoria possibilitará conhecer o perfil dos docentes em sua trajetória acadêmica e profissional, e também conhecer o perfil dos discentes. Na segunda categoría, buscou-se conhecer o entendimento e o conhecimento das práticas metodológicas, científicas e pedagógicas dos cinco profesores sujeitos dessa pesquisa, para que se possa aproximar ou até mesmo responder à questão norteadora desse trabalho, no que se refere ao conhecimento docente.

\section{Justaposição e Comparação}

A justaposição, terceira fase da pesquisa, é considerada fase-chave, na qual os dados coletados anteriormente (descritos e analisados) são observados em analogia aos elementos que se quer equiparar. As informações obtidas permitiram correlacionar semelhanças e diferenças de maneira objetiva, observando-se, assim, como os parâmetros se comportam nos diversos tipos de registros.

Nas comparações dos parâmetros e indicadores, sugerem-se alguns caminhos, como: (a) começar a avaliação pelo resultado geral, seguindo para o particular; (b) as referências devem ser realizadas partindo dos valores máximos para os mínimos e, por último, os médios; (c) observar as convergências (dados que se aproximam da média, semelhanças e valores mais repetidos), as divergências (particularidades, valores mais distantes da média ou de menor frequência) e as tendências (os dados nos permitem hipotetizar); e (d) explicar e avaliar os fatores prementes.

Essa etapa exige um cuidado especial do comparador, na qual, ele, mediante a junção de todas as informações, tendo em vista o objetivo da comparação, averigua o que relatam os dados e, a partir desses dados, emite a conclusão, pautada no processo investigativo e na objetividade dos elementos.

Assim, de acordo com a construção dos parâmetros, categorias e indicadores, apontados no Quadro 1, destacam-se os seguintes aspectos: perfil do profissional docente e discente e 
Revista Educação e Políticas em Debate - v. 10, n. 2, p. 819-837, mai./ago. 2021 - ISSN 2238-8346 conhecimentos científicos, assim como pedagógicos e metodológicos, observados a partir dos cadernos dos alunos e que envolverão abordagem e desenvolvimento do tema, bem como as avaliações e planejamentos elaborados pelos professores.

Dessa forma, iniciou-se a justaposição e a comparação relacionadas às categorias elencadas, que nos remetem ao perfil dos cinco profissionais docentes que lecionaram, em 2017, no primeiro ano do Ensino Médio da EEGIP, e o perfil dos alunos que compuseram essas turmas, indicadas pelos professores.

Para comparar a qualificação profissional dos prodessores sujeitos dessa pesquisa, retomamos os dados estatísticos, verificando que o Brasil contava, em 2015, com aproximadamente 2,1 milhões de docentes da Educação Básica, envolvendo todas as redes. Desse total de docentes, um quarto não possuía curso superior. Entre os graduados, apenas 32,8\% atuavam em suas áreas específicas, no Ensino Fundamental, e 48,3\% no Ensino Médio, em consonância com o Anuário Brasileiro da Educação Básica (2016).

No estado de Minas Gerais, no que se refere à formação inicial, os professores da Educação Básica com graduação representavam 74,7\%, dos quais 31,3\% possuíam pósgraduação. Em Ituiutaba, de acordo com o Plano Decenal Municipal de Educação (PDME, 2015), 31\% dos docentes possuíam pós-graduação; porém estimava-se que 10\% dos professores não tinham licenciatura.

No que se refere à formação inicial e continuada dos cinco professores sujeitos da pesquisa (professor 1, professor 2, professor 3, professor 4 e professor 5), observa-se que, de modo geral, eles investem e/ou investiram em sua formação. Ressalta-se, também, que os anos de término da formação inicial entre os professores foram distintos, constituindose, aproximadamente três décadas, o que nos remete a séculos diferentes e contextos culturais distantes. Nesse sentido, Marcelo (2009) elucida que o trabalho docente pode ser transformado e dinamizado, tendo em vista o contexto local ou global no qual o profissional está inserido em um proceso individual ou coletivo.

No que tange ao tempo de serviço na educação dos discentes da pesquisa, o mesmo varia de dois anos (professor 3) a 31 anos (professor 1). Nota-se que são tempos bastante distintos, chegando a uma diferença, entre eles, de 29 anos, o que nos remete a questões culturais e sociais diferenciadas. Provavelmente, as identidades profissionais desses docentes foram constituídas de forma diferente, devido às vivências da trajetória profissional. Nessa óptica, o Plano Nacional de Educação (PNE) (BRASIL, 2014) foi instituído com o objetivo de estabelecer políticas públicas de valorização de professores e o fortalecimento do sistema de ensino, pois, quanto mais sustentável e integrada for a profissão docente, maior será a perspectiva de equidade educacional. 
Revista Educação e Políticas em Debate - v. 10, n. 2, p. 819-837, mai./ago. 2021 - ISSN 2238-8346

Na premissa de que a trajetória do professor envolve também seu desenvolvimento e formação, Garcia (1999) apregoa que essa formação inclui investigação, processo individual ou coletivo, teórico e prático, que permitem ao professor intervir positivamente no desenvolvimento do currículo, do ensino e do ambiente escolar, tendo em vista uma educação de qualidade. $\mathrm{O}$ autor cita que formar se refere à busca do indivíduo por mudanças próprias e desejadas, realizadas por meios oferecidos ou recursos próprios.

O professor pode se valer da formação continuada para ajudá-lo a se tornar um profissional competente. Nessa dialógica, Marim (2011) destaca que os professores competentes vão além da capacidade de resolver situações técnicas; eles desenvolvem várias habilidades, dentre elas: realizar análise de conflitos, propor conexões e conciliações; dominar saberes e conhecimentos, tendo em vista a sua organização e comunicação; desenvolver a visão integradora das práticas pedagógicas e proporcionar a conexão da escola e sociedade.

No percurso educacional dos cinco professores, de acordó com dados concernentes aos relatórios do conselho de classe e ao registro nos cadernos dos alunos do $1^{\circ}$ ano da EEGIP (2017), foram pontuados certos atributos, que nos remetem à ideia de competência docente, tais como: domínio dos saberes vislumbrando a organização e comunicação; desenvolvimento dos conteúdos; preocupação com os níveis de aprendizagem dos alunos; envolvimento dos alunos em suas práticas; gestão da prática pedagógica e questões disciplinares dos alunos.

Refletindo sobre a competência do professor e conjecturando a valorização desses profissionais, Nóvoa (2009) pondera sobre os discursos em pauta e a sua pouca aplicabilidade no contexto real, como: perspectivas de melhoras na profissão docente, que envolvem articulações entre a formação inicial e formação continuada; acompanhamento dos primeiros anos de exercício dos docentes; valorização do professor reflexivo; formação para investigação e pesquisa; trabalho em equipe; importância de culturas colaborativas; e acompanhamento dos docentes por equipes de especialistas, dentre outros.

Complementando a ideia sobre a valorização do professor, Marcelo (2009) reforça a necessidade de firmar sua identidade, a maneira como os docentes se definem, pautados na construção de suas práticas e do seu desenvolvimento integral, pensando em subidentidades e procedimentos evolutivos de experiências que incitem o sentido de pertença. Marim (2011) explicita que uma forte identidade profissional está associada ao aprimoramento de ações individuais e interpessoais, no intuito de ressignificar o ambiente educacional e de compartilhar conhecimentos e saberes entre pares.

O termo "saberes", na perspectiva de Paquay et al. (2005), nos remete à atitude de 
Revista Educação e Políticas em Debate - v. 10, n. 2, p. 819-837, mai./ago. 2021 - ISSN 2238-8346 compreender, de conhecer e saber fazer, e está relacionado às experiências vivenciadas pelos indivíduos. Assim, os autores relatam que, no saber, a informação é de ordem social, é exterior ao tema.

Os saberes e conhecimentos dos cinco professores decorrem de currículos e programas educacionais instituídos em diferentes épocas, com objetivos díspares e, consequentemente, apresentam saberes experienciais bastante divergentes. O grupo dos professores do $1^{\circ}$ ano da EEGIP se diferencia pela idade, tempo de graduação, iniciação na atividade docente e níveis de formação continuada, e o compartilhamento de ações e experiências na construção de saberes escolares possivelmente se firma no ambiente escolar.

Constata-se que os cinco professores tiveram formações acadêmicas diferenciadas, mas com tradições que perduraram e alguns conhecimentos disciplinares comuns, como, por exemplo, a linguagem Matemática. No entanto, com o transcorrer dos anos, mudanças significativas ocorreram nos currículos das universidades, tais como: estágios mais estruturados, aspectos metodológicos diferenciados, inserção de recursos tecnológicos nas ações docentes, preocupações ambientais, ensino por meio de projetos e outros aspectos da contemporaneidade. Essas diferenciações entre os processos formativos dos professores e formação profissional influenciam muito nos conhecimentos científicos, pedagógicos, metodológicos e nas práticas.

Considerando a docência como ação educativa e processo pedagógico intencional e metodológico, as DCN (BRASIL, 2015), trazem orientações sobre o trabalho dos profissionais do magistério e a gestão educacional dos estabelecimentos de ensino da Educação Básica. Essas orientações envolvem vários princípios e objetivos, abordando diversas perspectivas, tais como: conhecimentos específicos ou interdisciplinares; recursos tecnológicos; aspectos políticos; valores culturais e éticos; inovações e diálogos entre diferentes concepções de mundo e formação para o mercado de trabalho.

Analisando o registro dos alunos, dados da pesquisa denotam que o trabalho dos professores no desenvolvimento do conteúdo de conjuntos numéricos não envolveu projetos ou qualquer outro tipo de ações entre pares. Percebe-se que cada professor desenvolveu esse conteúdo em tempo e de forma individualizada, sem conexão entre eles, e observa-se que não houve espaço para discussão de metodologia ou estudos referentes à parte científica, apesar de compartilharem as mesmas séries na escola.

Nos meandros da aprendizagem, Nóvoa (2009) defende a necessidade de propiciar a todos os alunos o acesso a uma base comum de conhecimentos e a possibilidade de percorrerem diferentes caminhos educacionais, para que essa escola faça sentido em suas vidas. O autor sugere que promover a aprendizagem é favorecer novas formas de pensar e trabalhar na escola, 
Revista Educação e Políticas em Debate - v. 10, n. 2, p. 819-837, mai./ago. 2021 - ISSN 2238-8346 é construir conhecimentos intrínsecos em caminhos pessoais, propor trabalho interdisciplinar, sem descartar a tradicionalidade das disciplinas, é o conhecimento escolar paralelamente conectado aos conhecimentos científicos.

O contexto social e cultural do aluno pode ser um elemento importante na relação docente/discente, que poderá ser harmoniosa e propiciar uma interação profícua, favorecendo o processo de ensino e aprendizagem. Ao traçar o perfil da turma, levou-se em conta: o número de alunos, faixa etária, questões disciplinares, escola onde o aluno concluiu o Ensino Fundamental e participação nas práticas pedagógicas. Observa-se que o total de alunos da escola, desses primeiros anos, é bastante significativo; as salas, em âmbito geral, estão ocupadas em sua capacidade máxima.

Os planejamentos dos professores, no que se refere à metodologia utilizada, mencionaram que seria utilizada aula expositiva, com exercícios para fixação, mas não detalharam como seriam as ações pedagógicas. Apesar de os planejamentos não possibilitarem um olhar sobre a metodologia desenvolvida em sala de aula, pelo registro dos cadernos dos alunos, observou-se que foram desenvolvidas atividades em grupo, elaboração e discussão de problemas apresentados.

Como fruto da observação dos cinco cadernos dos alunos do $1^{\circ}$ ano do Ensino Médio, indicados pelos cinco professores, temos um panorama geral dos aspectos teóricos e metodológicos do trabalho dos docentes, tendo em vista a parte científica correlacionada com suas práticas educacionais. Assim, foram contemplados os registros do desenvolvimento do conteúdo, exemplificações, problematizações, representações e processos que possivelmente favorecem a aprendizagem dos discentes.

No processo de apreensão, as representações semióticas, nas proposições de Durval (2012), são essenciais, e podem ser representadas por meio de figuras, gráficos, escrituras simbólicas, fórmulas, língua natural etc. Dados da investigação revelam que as representações semióticas foram priorizadas pelos professores quando os docentes propuseram a transposição da linguagem usual para a linguagem matemática, ressaltada por quatro professores, sendo aprofundada pelos professores 1, 3 e 4 .

Dados alusivos à valorização do registro no caderno dos alunos demonstram que os professores 1, 2 e 5 organizaram o registro de forma parcial; no entanto, os professores 3 e 5 contemplaram a valorização de registros com diversas atividades e abordagens. No que se refere ao desenvolvimento do conteúdo, os cadernos possibilitaram observar que a revisão de conteúdos foi priorizada pelos cinco professores, assim como conceituações e exemplificações.

Peretta e Souza (2005) e Chartier (2012) comentam sobre a importância do caderno como recurso didático e fonte de informação para compreender o cotidiano do aluno. Por meio 
Revista Educação e Políticas em Debate - v. 10, n. 2, p. 819-837, mai./ago. 2021 - ISSN 2238-8346 das anotações dos alunos, podem-se coletar informações e identificar como os procedimentos educacionais se processam e se inserem no ambiente educativo.

Considerando o processo avaliativo como peça fundamental no ensino e aprendizagem, analisou-se as avaliações apresentadas pelos registros dos alunos e outras fornecidas pela equipe pedagógica da EEGIP. As avaliações foram bastante distintas e divergentes, e observou-se que os objetivos propostos abordaram os seguintes aspectos: leitura e interpretação de situações-problema; resolução de problemas; operações com conjuntos numéricos; diversos tipos de representações; operações com intervalos organizados e diagrama de Venn Euler.

Chartier (2012) relata que a escrita diária reforça o sentimento de sucesso na aprendizagem. Nesse processo, o aluno se torna apto para escritas mais longas e elaboradas. Por meio dos registros nos cadernos é possível averiguar retrocessos e avanços de aprendizagem, podendo-se traçar o perfil da classe. A referida autora observou nos registros das avaliações resolvidas nos cadernos que a retomada de conteúdo sobre conjuntos numéricos foi priorizada por meio da correção dessas avaliações, juntamente com os alunos. Por meio desses registros, foram pontuados os principais aspectos considerados no processo avaliativo, permitindo sanar as dúvidas, podendo contemplar o desenvolvimento cognitivo do aluno.

\section{Considerações}

Para responder às indagações do problema inicial e atender às perspectivas do objetivo geral e objetivos específicos, essa produção científica procurou explorar o cenário sociopolítico, cultural e econômico brasileiro, permitindo, assim, a análise de dados relevantes e a construção do perfil do panorama do país de forma abrangente. Foram situadas, nessa dinâmica, as realidades do Brasil, do estado de Minas Gerais, do município de Ituiutaba e da Escola Estadual Governador Israel Pinheiro. O processo investigativo, por meio da metodologia de educação comparada, visou possíveis contribuições para a formação de professores e acessou documentos oficiais, concernentes a vários aspectos.

Nessa óptica, foi abordada a economia do Brasil, que se destaca no contexto da América do Sul e atualmente se encontra em desenvolvimento, com várias possibilidades de atividades econômicas. Ressalta-se, também, que por se tratar de um país de grande extensão territorial, as diferenças geográficas são acentuadas, o que propicia graves diferenças sociais.

Nesse sentido, a população é numerosa, dividindo-se em classes sociais díspares e 
Revista Educação e Políticas em Debate - v. 10, n. 2, p. 819-837, mai./ago. 2021 - ISSN 2238-8346 culturalismo diverso, originário de fontes migratórias distintas. No contex to brasileiro, inserese o estado de Minas Gerais e o município de Ituiutaba, ambos constituídos pela mistura de diversos povos, com aspectos culturais distintos e com grande importância para o desenvolvimento do Brasil, nos contextos econômicos, políticos e sociais. Mesmo diante das prerrogativas positivas desse estado e município, existem fragilidades a serem superadas, que precisam de um olhar diferenciado, tais como: desigualdades sociais, crises políticas, desemprego e problemas na educação e saúde.

No que tange ao Brasil, informações revelam que têm sido realizados investimentos significativos na educação, nas diversas autarquias administrativas (país, estado e município). Entretanto, os processos avaliativos sistêmicos indicam que os resultados têm sido inexpressivos. Nesse meandro, a pontuação avaliativa da EEGIP está acima das demais autarquias administrativas, no que se refere ao IDEB (Índice de DEsenovimento da Educação Básica) e Sistema Mineiro de Avaliação da Educação Pública (SIMAVE). Contudo, esses resultados não significam apenas aspectos positivos, pois, assim como no país, no estado e no município, a escola também apresenta uma parcela significativa de alunos que precisam consolidar habilidades básicas de conhecimentos.

Considerando-se os resultados dessas avaliações, percebe-se a necessidade de refletir sobre a aplicação de investimentos na educação, redirecionar as políticas públicas, analisar o currículo e propor estratégias em que haja uma base comum de conhecimentos em todas as regiões do país, em que todos os alunos tenham acesso a aprendizagens elementares.

Ressalta-se que aproximadamente $85 \%$ dos alunos no Brasil estão sob a responsabilidade da educação pública, obrigatória e gratuita, compondo um contingente numeroso sob a responsabilidade dos órgãos governamentais. É necessário reavaliar, fomentar e manter políticas públicas efetivas, que tenham continuidade independentemente dos mandatos de governos e que priorizem a qualidade da educação nas esferas estaduais e municipais, que enfrentam sérios problemas na construção do conhecimento e na administração do sistema escolar.

Uma realidade que se contrapõe às situações mencionadas são as escolas federais, que são bem estruturadas nos aspectos físicos, pedagógicos e cognitivos. Sugere-se implementar e manter políticas educacionais que elevem a qualidade da educação pública estadual e municipal, por meio da valorização dos professores; promoção à formação continuada; propiciação de salários adequados; melhorias nas condições de trabalho e propostas de políticas educativas que se assemelhem à categoria da educação federal.

Compreendendo o município de Ituiutaba e a EEGIP, dados concernentes aos cinco docentes inseridos na pesquisa demonstram que o grupo de professores é eclético e divergem 
Revista Educação e Políticas em Debate - v. 10, n. 2, p. 819-837, mai./ago. 2021 - ISSN 2238-8346 diversos aspectos: idade, ano de conclusão da graduação, tempo de serviço na educação, tempo de atuação na escola e tempo disponibilizado para a formação continuada. Essas realidades nos remetem a perspectivas profissionais diferentes, que permeiam a formação inicial e também o exercício da profissão docente.

Observam-se realidades de professores que terminaram sua graduação recentemente, no auge da era tecnológica, quando as informações e inovações se processam aceleradamente. Esse grupo de professores se contrapõe aos que concluíram o ensino superior nos anos 1980, antes da inserção e expansão dos recursos tecnológicos no ambiente escolar. Esses fatos implicam em distintos conhecimentos acadêmicos, didáticos e metodológicos e também em saberes construídos por meio das diversas fases experienciadas profissionalmente, marcados por contextos sociais diversos.

Ressalta-se, também, que essas vivências envolvem competências no lidar com situações cotidianas que paulatinamente vão formando concepções, visões preponderantes, constituindo, assim, a identidade e os princípios do ser professor. Refletindo sobre essas perspectivas, indica-se o compartilhamento de fazeres e saberes desses professores que apresentam bagagens culturais díspares e muito podem contribuir na aprendizagem entre pares.

A aprendizagem discente também foi considerada e observada sob a perspectiva das ações docentes nesse processo, na premissa da inter-relação entre ambos, já que a construção do conhecimento envolve ações mútuas para que aconteça de forma eficiente.

Dados das fichas do conselho de classe dos professores do $1^{\circ}$ ano revelaram que as turmas investigadas quase não apresentavam problemas disciplinares; apenas uma turma exibiu situação mais agravante, necessitando, por vezes, da intervenção da equipe gestora. Porém, isso não significa apenas resultados positivos, pois, em quatro turmas foram pontuados desinteresse e falta de participação nas atividades propostas pelos professores, o que atrapalha o rendimento escolar do aluno e acarreta dificuldades de aprendizagem em todas as áreas do conhecimento, incluindo a Matemática.

Atenta-se que a dificuldade de aprendizagem é fator sério e merece um olhar diferenciado pelo sistema educacional desde os anos iniciais até o Ensino Médio. Recomenda-se a implementação efetiva de salas de acompanhamento pedagógico para atender alunos com problemas de aprendizagem, com profissionais especializados (pedagogos e psicólogos) e professores que desenvolvam um ensino mais dinâmico, como, por exemplo, projetos e oficinas.

Dados concernentes aos conhecimentos científicos, pedagógicos e metodológicos, desvelam que as formas de desenvolvimento do conteúdo de conjuntos numéricos pelos cinco 
Revista Educação e Políticas em Debate - v. 10, n. 2, p. 819-837, mai./ago. 2021 - ISSN 2238-8346 professores foram bastante divergentes, mesmo partindo de planejamentos anuais similares. A disponibilização de tempo para aplicação do conteúdo apontou uma diacronia significativa entre as práticas docentes - houve professor que aplicou o conteúdo em duas aulas, enquanto outros utilizaram doze dias, um mês e até mais.

Uma perspectiva importante foi a análise dos registros subsidiados pelos cadernos dos alunos, indicados pelos cinco professores, que constituíram a peça fundamental e fonte rica de informações no processo investigativo. Os cadernos revelaram vários aspectos: ações educativas dos alunos e professores, metodologias empregadas, tempo de aprendizagem e estruturação e desenvolvimento do conteúdo sobre conjuntos numéricos.

Assim, conclui-se que os conhecimentos e saberes docentes sobre conjuntos numéricos, em conexão com a resolução, foram apontados nas praxes dos professores do primeiro ano do Ensino Médio, por meio dos registros dos cadernos dos alunos, de formas distintas. Cada professor à sua maneira, no seu tempo, desenvolveu suas atividades, alguns ministraram esses conhecimentos de forma superficial e outros de maneira aprofundada.

Os registros desvelaram práticas individualizadas entre os cinco professores. Sugere-se, assim, a criação de um ambiente de partilha de conhecimentos, para discutir o planejamento anual, inteirar-se dos conteúdos a serem aplicados e, em sincronia, organizar as práticas educacionais diárias. Destaca-se, nesse processo, a importância do acompanhamento da equipe pedagógica com relação ao desenvolvimento dos conteúdos, na perspectiva de discutir orientações, metodologias, tempo previsto de aprendizagem e definir objetivos e ações elementares.

\section{Referências}

ANUÁRIO BRASILEIRO DA EDUCAÇÃO BÁSICA - ABEB. São Paulo: Editora Moderna, 2016.

BRASIL. Ministério da Educação. Conselho Nacional de Educação. Diretrizes Curriculares Nacionais para a formação inicial em nível superior e para a formação continuada. Resolução CNE/CP 2, de 1 de julho de 2015. Disponível em: http://portal.mec.gov.br/index.php?option=com_docman\&view=download\&alias=17719-rescne-cp-002-03072015\&category_slug=julho-2015-pdf\&Itemid=30192. Acesso em: 01 mar. 2021.

BRASIL. Ministério da Educação. Base Nacional Comum Curricular. Brasília, 2018. Disponível em: http://basenacionalcomum.mec.gov.br/. Acesso em: 28 fev. 2021.

BRASIL. Plano Nacional de Educação (PNE) 2014-2024. Lei n ${ }^{\circ}$. 13.005, de 25 de junho de 2014. Brasília: Câmara dos Deputados, Edições Câmara, 2014. Disponível em: http://www.observatoriodopne.org.br/uploads/reference/file/439/documentoreferencia.pdf. Acesso em: 28 fev. 2021. 
CABALLERO, A.; MANSO, J.; MATARRANZ, M.; VALLE, J. M. Investigación en Educación Comparada: Pistas para investigadores noveles. Revista Latinoamericana de Educación Comparada. Estudios e Investigaciones, p. 39-56 / relec / Año 7 Nº 9 / 2016 / ISSN 1853-3744. Disponível em: http://www.saece.com.ar/relec/revistas/9/art3.pdf. Acesso em: 10 mar. 2021.

CHARTIER, A. M. Caderno: vitrine da classe, espelho do aluno. Revista Nova Escola Digital, 2012. Disponível em: https://novaescola.org.br/conteudo/544/caderno-vitrine-daclasse-espelho-do-aluno. Acesso em: 28 fev. 2021.

DUVAL, R. Registros de representação semiótica e funcionamento cognitivo do pensamento. (Trad. Méricles Thadeu Moretti). REVEMAT: R. Eletr. Educ. Mat., UFSC/MTM/PPGECT, Florianópolis, SC, Brasil, ISSN 1981-1322. v. 7. 2012. DOI: https://doi.org/10.5007/19811322.2012v7n2p266. Disponível em:

https://periodicos.ufsc.br/index.php/revemat/article/view/1981-1322.2012v7n2p266. Acesso em: 28 fev. 2021.

FREIRE, M. O papel do registro na formação do educador. Plenário Virtual: educação e tecnologia, 2009. Disponível em: https://plenariovirtual.blogspot.com/2009/01/o-papel-doregistro-na-formao-do.html. Acesso em: 10 mar. 2021

GARCIA, C. M. Formação de Professores: para uma mudança educativa. Porto/Portugal: Editora Porto, 1999.

MARCELO, C. Desenvolvimento Profissional Docente: passado e futuro. Sísifo. Revista de Ciências da Educação, 08, pp. 7-22. 2009. Disponível em: http://www.unitau.br/files/arquivos/category_1/MARCELO_Desenvolvimento_Profiss ional_Docente_passado_e_futuro_1386180263.pdf. Acesso em: 17 fev. 2021.

MARIM, V.; MANSO, J. A formação inicial do professor de educação básica no Brasil e na Espanha. Salamanca: Fahren House, 2018. Disponível em:

file:///C:/Users/vlade/Downloads/26-3-75-1-10-20180207.pdf. Acesso em: 10 mar. 2021.

MARIM, V. Formação Continuada do Professor que ensina Matemática nas Séries Iniciais do Ensino Fundamental: um estudo a partir da produção acadêmico-cientifica brasileira. 2011 , 217 f. Tese (Doutorado em Educação) - Pontifícia Universidade de Católica de São Paulo, 2011. Disponível em: https://tede2.pucsp.br/bitstream/handle/9551/1/Vlademir\%20Marim.pdf. Acesso em: 10 mar. 2021.

NÓVOA, A. Professores Imagens do futuro presente. EDUCA. 1649-013 Lisboa | Portugal. 2009. p. 17. Disponível em: http://pt.slideshare.net/mzylb/antonio-novoa-novolivro?from action=save. Acesso em: 28 jun. 2020.

PAQUAY, L.; ALTET, M.; CHARLIER, E.; PERRENOUD, P. (Coords). La formación profesional del maestro. Estrategias y competencias. 2005. (Trad. de Consol Vilá) ISBN 968-16-7544-4. México: FCE, 2005.

PERETTA, A. A. C. S.; SOUZA, M. P. R. Cadernos escolares: como e o que se registra no contex to escolar. Psicologia Escolar e Educacional, Campinas, v. 9, n.2, p. 291-302, 2005. Disponível em: http://pepsic.bvsalud.org/scielo.php? script=sci_arttext\&pid=S1413$85572005000200011 \& \operatorname{lng}=$ pt\&nrm=iso. Acesso em: 14 fev. 2021. 
Revista Educação e Políticas em Debate - v. 10, n. 2, p. 819-837, mai./ago. 2021 - ISSN 2238-8346

PUENTES, R. V.; AQUINO, O. F.; NETO, A. Q. Profissionalização dos professores: conhecimentos, saberes e competências necessários à docência. Educar em Revista, v. 34, p. 169-184, 2009. DOI: https://doi.org/10.1590/s0104-40602009000200010. Disponível em: http://www.scielo.br/pdf/er/n34/10.pdf. Acesso em: 10 jan. 2021.

TARDIF, M. Saberes profissionais dos professores e conhecimentos universitários.

Revista Brasileira de Educação. Jan./fev./mar./abr. 2000, n. 13. Faculté des Sciences de l'Éducation, Université Laval. Disponível em:

http://www.joinville.udesc.br/portal/professores/jurema/materiais/RBDE13_05_MA URICE_TARDIF.pdf. Acesso em: 28 jan. 2021. 